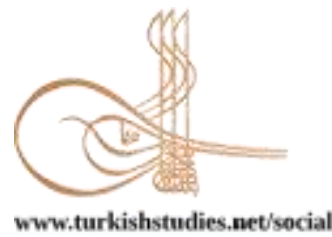

Turkish Studies - Social Sciences

eISSN: $2667-5617$

Research Article / Araştırma Makalesi

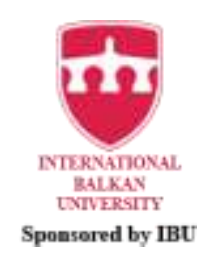

\title{
Hüseyin Nihal Atsız'ın Bozkurtlar Romanında Boş Zaman ve Oyun Figürleri
}

The Figures of Leisure and Play In The Hüseyin Nihal Atsiz's Bozkurtlar Novel

\author{
Hakan Çetiner*
}

\begin{abstract}
Hüseyin Nihal ATSIZ describes the steppe life of the period through historical characters that structured on the history of Göktürks in the Bozkurtlar novel. In this study, Atsız is the subject of Turkish Ethics and the social morality of Turks, but also provides information about the daily lives of Turks. The aim of this study is to determine the leisure activities of Turks in steppe life in light of what Atsiz told us about and to have knowledge about the culture of play and entertainment of the period. The novel consists of two parts: "Bozkurtların Ölümü" and "Bozkurtlar Diriliyor" that events were experienced in different geographies. The presence of different cultures in these geographies is also important in terms of revealing the effect of social morality and the geography on the leisure habits of societies. Considering the conditions of time in the novel, the concept of leisure and the activities of the individuals were evaluated in the context of game theories. The Study in this aspect; It is a social time study that focuses on social life elements such as life style, beliefs, customs and traditions, entertainment types, competitions and ceremonies. The most striking aspect of the games played in the steppe life is that they are regular games. Complying with the rules is equivalent to following the Turkish Ethics. The theory of readiness to life, which is a kind of game theories, is seen as an approach defining the aims of children who are prepared for adult games and their later lives in steppe life. Children are prepared for their future lives through experiences of actions related to later life through play. As a result of socio-cultural development theory, the same children learn the rules of Turkish Ethics with play.
\end{abstract}

Structured Abstract: Recreational activities that Turks participate in their leisure time are a part of their culture. Addressing the Göktürkler period and the steppe life meticulously with historical facts, Atsız gives information about his beliefs, traditions and customs, entertainment and play activities, which are the social time elements of the period. The novel, which has been examined in terms of social time items, has only been examined in terms of leisure habits and culture of play and entertainment. The social time elements in the novel were evaluated in terms of leisure and game theories, and the culture of play and entertainment was determined.

When the time described in the novel is examined according to the purpose of use; It is observed that the activities that constitute the basic working time of the period and the basic physiological needs within the time periods required for compulsory activities are composed of the occupations of different professional groups such as raids, agriculture and animal husbandry, hunting, trade and blacksmithing. In addition, activities in which family and social responsibilities are fulfilled are also within the timeframe required for compulsory behavior. Given the social needs, it is not possible to speak of a clear distinction between compulsory time and

\footnotetext{
* Öğr. Gör. Dr., Ankara Hacı Bayram Veli Üniversitesi, Turizm Fakültesi, Rekreasyon Yönetimi Bölümü Lect. Dr., Ankara Hacı Bayram Veli University, Faculty of Tourism, Department of Recreation Management. ORCID 0000-0002-6370-2953

hakan.cetiner@hbv.edu.tr

Cite as/ Atıf: Çetiner, H. (2020). Hüseyin Nihal Atsız'ın Bozkurtlar romanında boş zaman ve oyun figürleri. Turkish

Studies - Social, 15(4), 1837-1851. https://dx.doi.org/10.29228/TurkishStudies.41707

Received/Geliş: 10 February/Şubat 2020

Checked by plagiarism software

Accepted/Kabul: 20 June/Haziran 2020

Published/Yayın: 25 June/Haziran 2020

Copyright $($ INTAC LTD, Turkey

CC BY-NC 4.0
} 
leisure time. In some cases, "hunting", which is performed as a leisure time behavior, turns into compulsory behavior during times of famine or starvation. Similarly, sword, arrow exercises, wrestling and horse riding activities carried out as a raid or preparation for war are a mandatory behavior; Those performed in toy, ceremony and feasts are seen as a leisure behavior. For this reason, in order to distinguish between compulsory and leisure behaviors, the structure and social needs of the time in the period must be determined correctly.

When spatial leisure behaviors are examined; It is seen that the qualitative features of the place have an effect on leisure time activities and game types. The geography and climate conditions of the Turks directly affect their leisure culture. The tools and equipment they use in daily life are the decisive aspects of the types of games and what the tools they use in the game will be. For this reason, archery, sword play, wrestling, horseplaying games are the most prominent examples of games.

The geographical location of the Turks in the period of freedom is the city of Ötüken in the steppe, and the geographical location in the period of captivity is the capital of China, Siganfu. Leisure activities in the steppe life differ from those in the city life, and differences in terms of rural and urban recreation types are noticeable in the novel.

There are many types of entertainment that Turks call Khaganate celebration, toy, feast, and celebration. After victory, when the kagan changes, spring comes, before important raids and envoys come, this kind of entertainment is organized. In these celebrations, sword games, marksmanship, archery, wrestling, horse racing and games and award-winning competitions are held. Although it is a leisure-time activity, it is also seen that there are activities carried out to gain status and value in front of the Kagan and in the society. Leisure behaviors in Turks present value to the individual and society.

In the entertainment genres and the steppe life of the Turks, the bards have an important place. Bards are not only an element of entertainment and game culture, but also those who take part in uncovering feelings of war and heroism. Apart from the relaxing and entertaining functions of toy, festivity, entertainment and travel breaks, it has motivating soldiers in times of war. In addition, drums, kopuz, pipings are among the musical instruments in the music and entertainment culture of the period. It is determined that today's minstrel tradition is a kind of activity that remains from the life of steppe.

The games in the steppe life have rules, and following these rules is equivalent to following the Turkish Ethics. It is seen that the rules of the games such as capricorn grabbing, archery, marksmanship, wrestling, horse racing, sword play are clearly followed.

Most of the game examples in the novel are games applied for adults. The types of games played for children are the same games as adults. Only the tools they use, such as swords, arrows, bows, are not tools used by adults. Girls, like boys, play swords, shoot arrows and ride horses. A gender-equitable profile is drawn in the steppe life. "Preparation to life theory", which is one of the game theories, is an approach that defines the aims of children who are prepared for their later lives with adult games in the steppe life. Children are prepared for their future lives by experiencing the actions of later life through play. The same children learn the rules of the Turkish Ethics through play as a requirement of the "socio-cultural development theory".

There is a strong relationship between culture and leisure time habits. As the Turks become accustomed to the cultures of the communities they interact with, they are weak in fulfilling the requirements of their own cultures. As they move away from their own culture, they move away from leisure traditions, and as they move away from their leisure traditions, they leave their own culture. While there are Turks who continue their own activities in order to preserve and maintain their own culture even in other geographies in captivity, it is seen that Turks, who have moved away from their own identity, have moved away from them and become alienated from them. It reflects the Turks' Ethic and identities. It moves away from one another and away from the other. Turks, who do not leave their culture even if they leave their countries and states, use their free time in accordance with the ceremony. In fact, it is seen that the ones who experience traditional leisure activities are the ones who make the ethic.

Keywords: Recreation Management, Atsız, Bozkurtlar, Recreation, Play and Fun.

Öz: Hüseyin Nihal ATSIZ Göktürklerin tarihi üzerine kurguladığı "Bozkurtlar” romanında, dönemin bozkır hayatını tarihi karakterler üzerinden anlatmaktadır. Atsız bu eserinde, Türk Töresi ve Türklerin toplumsal

Turkish Studies - Social, 15(4) 
ahlakını konu edinmekle birlikte, Türklerin gündelik yaşamları hakkında da bilgiler sunmaktadır. Bu çalışmanın amacı, Atsız'ın anlattıkları 1şı̆̆ında bozkır hayatında Türklerin katıldıkları boş zaman aktivitelerini belirleyerek, dönemin oyun ve eğlence kültürü hakkında bilgi sahibi olmaktır. Romanı oluşturan "Bozkurtların Ölümü" ve "Bozkurtlar Diriliyor" adlı iki bölümde yaşanan olayların farklı coğrafyalarda geçmesi, bu coğrafyalarda farklı kültürlerin bulunması, toplumsal ahlâk ve yaşanılan coğrafyanın toplumların boş zaman değerlendirme alışkanlıklarına etkisini ortaya koyması açısından da önemlidir. Romanda geçen zamanın şartları göz önünde bulundurularak boş zaman kavramı irdelenmiş ve bireylerin katıldıkları aktiviteler oyun kuramları bağlamında değerlendirilmiştir. Bu yönüyle çalışma; dönemin yaşam şekli, inançları, gelenek ve görenekleri, eğlence türleri, yarışmaları, törenleri gibi sosyal yaşam öğelerini rekreasyonel açıdan konu edinen bir sosyal zaman incelemesi niteliğindedir. Bozkır hayatında oynanan oyunların en dikkat çekici tarafı kurallı oyunlar olmasıdır. Kurallara uymak töreye uymakla eş değerdir. Oyun kuramları içerisinde "yaşama hazırlık kuramı" bozkır hayatında yetişkin oyunları ile sonraki yaşamlarına hazırlanan çocukların oyunlara katılma amaçlarını tanımlayan bir yaklaşım olarak görülmektedir. Çocuklar oyun yoluyla hayatın ileri dönemlerine iliş̧in eylemlerin deneyimlerini yaparak gelecekteki yaşamlarına hazırlanmaktadırlar. Aynı çocuklar "sosyokültürel gelişim kuramı”nın gereği olarak oyun yoluyla Türk töresinin kurallarını öğrenmektedirler.

Anahtar Kelimeler: Rekreasyon Yönetimi, Atsız, Bozkurtlar, Rekreasyon, Oyun ve Eğlence.

\section{Giriş}

Türk kültürünü yaşatmak konusunda önemli bir misyona sahip olan tarihi romanlar; geçmiş ile gelecek arasında bir bağ oluşturarak özelde okuyucuya genelde Türk toplumuna tarih şuuru aşılamak amacıyla kaleme alınmaktadır. Savaş ve kahramanlık hikâyelerinin yanı sıra Türk töresi ve yaşam tarzı hakkında bilgiler sunarak, kültürel değerlerin korunması ve gelecek nesillere aktarılmasında hayati rol üstlenmektedir. Bu yönüyle tarihi romanlar yalnızca edebi metinler olmanın ötesinde bir milletin hafızasını oluşturan eserlere dönüşmektedir. Konu edindikleri dönemin yaşam şartları ile toplumun gelenekleri ve alışkanlıkları, tarihsel gerçeklere bağlı kalınarak toplumsal kültürün oluşmasını sağlamakta; tarihi bilgiler ışığında geçmişe yönelik bir bakış açısı getirmektedir.

Tarihi olayları ve gerçekleri yorumlamak, tarih şuuru oluşturmak anlamına gelmektedir. Güngör (2003: 66) tarih şuurunu "Tarihin akışı hakkında belli bir görüş sahibi olmak" şeklinde ifade etmekte ve "insanın tarih olaylarını mânâlı bir bütün içindeki parçalar hâlinde gördüğü anda "tarih şuuru" kazanmış olacağını" belirtmektedir. Bu bağlamda tarih şuurunun oluşması yalnızca kahramanlık hikâyeleri, savaşlar, yaşanan zorluklar ve atlatılan badirelerle sınırlandırılmamalıdır. Sosyal olaylar, dönemin yaşam tarzlarına ilişkin ipuçları, gelenekler, inançlar, eğlence ve oyun kültürü, törenler, düğünler gibi pek çok unsur, bu şuurun oluşturulmasına katkı sağlamaktadır.

Tarih bilinci ve sosyal hafiza bireyden topluma geçişte önemli bir yere sahiptir (Çetin, 2010). Tarihî romanlarda ele alınan olayın geçtiği dönemde toplumun sahip olduğu, bir kısmı sonra da devam eden hatta günümüze uzanan örf ve âdetler, davranış biçimleri, inançlar gibi hususlar zamanla bağlantıları olmaları açısından önemli olmaktadır (Topdemir, 2012). Geçmişten kök bulmak, yeni hâle getirmekle aynı mânâya gelmektedir. Şu hâlde geçmişin hiç değilse bir "sosyal hafıza" hâlinde bugünkü hayatımızda bulunması şart olmaktadır (Güngör, 2003: 73). Toplumlar sosyal hafızalarını geleneksel boş zaman davranışlarını devam ettirmek suretiyle sürekli diri tutmaktadırlar.

İslamiyet'in kabulünden önce, kültürel değerlerin korunması ve sonraki nesillere aktarılmasında masal ve destan türleri kullanılmıştır. İslamiyet'in kabulünden sonra hikâye türü metinler ve gazavâtnâmeler aynı görevi üstlenmiştir (Elvis, 2014). Türk edebiyatında tarihi roman türünün ortaya çıkışı Osmanlı tarihinin konu edildiği romanlarla olup, batılılaşma hareketlerinin hız kazandığı Tanzimat Dönemine rastlamaktadır. Cumhuriyet döneminden sonra ise tarihî romanlar, Türk kültürünün yaşatılmasında en çok tercih edilen roman türü olmuştur. Çalışmaya konu olan Hüseyin Nihal Atsız'ın "Bozkurtlar" romanı da Cumhuriyet Dönemi tarihi romanlarından olup, İslamiyet öncesi Türk tarihini konu alan dönemin nâdir eserlerindendir. Romanlarında millî değerlere sıkça rastlanan Atsız, Bozkurtlar romanında Göktürkler tarihi içerisinde Türklerin bozkır hayatını 
konu edinmiştir. Kafesoğlu (2018: 37) bozkır kültürünün temelde Türk olduğu ve gelişme boyunca da Türk topluluğunun karakterini muhafaza ettiğini ifade etmektedir.

Romanın ilk kısmını oluşturan 'Bozkurtların Ölümü' 1946 yılında, romanın ikinci kısmını oluşturan ‘Bozkurtlar Diriliyor' ise 1949 yılında yazılmıştır. 1973 yılında Ötüken Neşriyat tarafından birleştirilen bu iki roman daha sonraları "Bozkurtlar" ismini almıştır. Romanın ilk bölümü Göktürk Devleti’nin yıkılışını, ikinci bölümü ise tekrar kuruluşunu konu edinmektedir.

Tarihi romanlarda temel öge konu edinilen zamandır ve vaka zamanı, kozmik zaman ve sosyal zaman olarak üç farklı șekilde ele alınmaktadır (Topdemir, 2012). Vaka zamanı olayın geçtiği dönemi ifade etmektedir ve kronolojik bir seyir göstermesi beklenmektedir. Söz konusu romanda vaka zamanı, Göktürklerin yıkılış dönemidir ve romana konu edilen olaylar 621 yılının bir yaz gecesi başlamaktadır. İkinci bölümde ise Göktürklerin tekrar kuruluşu anlatılmaktadır ve romanda gerçekleşen olayların 621 yılı ile 680'li yıllar arasında kronolojik bir sırayla ilerlediği görülmektedir. Kozmik zamanda; yıl, mevsim, ay, hafta, gündüz, gece gibi ögelerin kullanış biçimleri ifade edilmektedir. Sosyal zamanda ise; dönemin siyasi yönleri, sosyal yaşamın belirgin özellikleri ortaya konulmaktadır. Yaşam şekli, inançlar, gelenek ve görenekler, düğünler, toylar, eğlence şekilleri, alışkanlıklar, yeme-içme kültürü, giyim tarzı, yarışmalar, törenler, unvan ve ad verme gibi sosyal yaşamın öğeleri ele alınmaktadır. Eski Türklerin sosyal ve kültürel kuruluşları hakkında aydınlatıcı bilgilere sahip olunmaması (Kafesoğlu, 2018: 325) ilgili dönemi konu alan tarihi romanları daha değerli kılmaktadır. Söz konusu roman, sosyal zaman ögeleri açısından incelenmiş olup belirtilen hususlardan yalnızca boş zaman alışkanlıkları ile oyun ve eğlence kültürleri irdelenmiştir. Bu sayede dönemin yaşam şekli, inançları, gelenek ve görenekleri, eğlence türleri, yarışmaları, törenleri gibi sosyal yaşam ögeleri belirlenerek, Atsız'ın anlattıkları 1şığında bozkır hayatında Türklerin katıldıkları boş zaman aktiviteleri ile dönemin oyun ve eğlence kültürü ortaya çıkarılmak istenmiştir. Romandaki sosyal zaman unsurları, boş zaman ve oyun kuramları perspektifinde değerlendirilerek, önce boş zaman kavramı dönemin çalışma hayatı göz önünde bulundurularak tespit edilmeye çalışılmış, daha sonra boş zaman davranışları ve etkinlikleri belirlenmiştir.

\section{Zamanın yapısı, özellikleri ve boş zaman}

Romandaki boş zaman etkinliklerini belirlemeden önce romanda anlatılan hikâyenin geçtiği zamanın boş zaman yaklaşımları açısından incelenmesi ve çalışma zamanı başta olmak üzere zorunlu davranışlar için gerekli olan zaman dilimlerinin ortaya konulması gerekmektedir. Zira boş zaman, bireyin bütün zorunluluk ve sorumluluklarından ayrı olarak istediği şekilde kullanabileceği bir zaman dilimini ifade etmektedir. Bu zaman dilimi kazanç sağlama ya da gelir elde etme amaçlı yapılan iş, bu işle bağlantılı etkinliklerin yapıldığ süreler, bireyin yaşamsal faaliyetlerine ilişkin gerçekleştirdiği etkinlikler ile ailesel ve toplumsal sorumluluklarını yerine getirdikten sonraki "bağımsız ve bağlantısız" bir zaman dilimini kapsamaktadır. Bu nedenle, romana konu olan dönem için boş zamanı belirleyebilmek, öncelikle dönemin zorunlu faaliyetlerini ortaya çıkarmakla mümkün olabilecektir.

Başta belirtmek gerekir ki; bozkırda yaşamanın zaruri kıldığı bazı ekonomik faaliyetler dışında Türk bozkır kültürünün göçebelikle bir ilgisi bulunmamaktadır. Türk bozkır kültürünün değerlerinden olan devlet kuruculuk, ordu teşkilatı, dini hoşgörülük, yaygın adalet, üniversel ülkücülük vb. gibi unsurlar derece derece bütün tarihi Türk devlet ve topluluklarında, Türk tesirinde kalmış milletlerde ve nihayet bütün dünyada yüzyıllarca yaşamaya devam etmiştir (Kafesoğlu, 2018:38). Bu sebeple Türklerin zorunlu davranışlarını ve temel geçim unsurlarını göçebe kültürü üzerinden yorumlamak bir yanılgıya sebep olmaktadır.

Romanda Göktürklerin temel geçim kaynağının akınlar üzerinden sağlandığı görülmektedir. Türklerin savaş̧̧ bir kimliğe sahip olmaları ve yakın coğrafyalarda farklı topluluklarla komşu olarak yaşamaları -özellikle nüfus olarak kendilerinden sayıca çok üstün olan Çinliler- akınlara daima hazırlıklı olmalarını zorunlu kılmaktadır. Romanın birçok yerinde akınlardan ve bu akınların 
sonunda elde ettikleri yağmalardan söz edilmektedir. Akın sonucu elde edilen ganimetlerin hayatlarını idame ettirmek ve kazanç sağlamak amaçlı yapılan bir "iş" niteliğinde olduğu görülmektedir. Toplumun ekonomisinin büyük çoğunluğunu akınlarda edilen ulcalar (ganimet) oluşturmakta ve akınlarda ne kadar çok elde edilirse budun o kadar zenginleşmektedir.

Akınlar dışında avcılık Göktürklerin geçim kaynaklarından bir diğerini oluşturmaktadır. Av sonrasında elde edilen av hayvanları hem gıda hem de alışveriş amaçlı olarak kullanılmaktadır. Bozkırlı Türklerin başlıca gıda maddesinin et olduğu gerçeği (Kafesoğlu, 2018: 305) yaptıkları işin niteliğini doğrudan etkilemektedir. Romanda geyik, tavşan, kuş gibi farklı türden av hayvanları için farklı avcılık metotlarından söz edilmektedir. Yaygın olarak kullanılan av malzemeleri ok ve yaylar olmasına rağmen farklı ok tiplerinin kullanıldığı da görülmektedir. İnce okla yapılan kuş avcıllığı (s.110), akdoğan (s.67) ve avcı doğan (s.185) gibi yırtıcı kuşlarla yapılan avcılık türleri ile sürek avcılığından (s.100-101) bahsedilmektedir. Avcılık alışveriş için mübadele aracı olarak kullanıldığ1 gibi savaş talimi için yapılan bir davranış türü olarak da görülmektedir.

Göktürklerde tarım, hayvancılık ve ticaret başka uğraşlar olarak görülmektedir. Her ailenin ekip biçtiği, suladığı bir arazisi bulunmaktadır. Hayvancılık kısrak besleme ve kısrak sütünden kımız yapmanın dışında, yününden kumaş yapmak için de gerçekleştirilen bir faaliyettir. Ayrıca bozkır hayatında önemli bir yere sahip olan kımızın "Orkun ırmağı kıyısında kızların kımız yaptıkları yer (s.60)" cümlesinden anlaşılacağı üzere bozkır kadınlarının yerine getirdikleri bir iş olduğu görülmektedir.

Dönemin ticari faaliyetlerinde Çin'le ilişkilerin önemli bir yeri olduğu söylenebilir. Akın zamanları dışında barış günlerinde, artan bir ticari faaliyet söz konusudur. Ayrıca kağan tarafından kış günlerinde alışveriş yapılması için yapılan kapalı mekân dönemin önemli bir ticari alanı ve günümüz alışveriş merkezlerinin ilk örneklerindendir.

Toplumsal gerekler göz önünde bulundurulduğunda, zorunlu zaman ve boş zaman arasında net bir ayrımdan söz etmek mümkün olamamaktadır. Bazı durumlarda bir boş zaman davranışı olarak yapılan "avcılık", kıtlık ya da açlık zamanlarında zorunlu davranışa dönüşmektedir. Benzer şekilde akın ya da savaş hazırlığı olarak gerçekleştirilen kılıç, ok talimleri ile güreş ve at binme faaliyetleri bir zorunlu davranış; toy, tören ve şölenlerde yapılanlar, bir boş zaman davranışı olarak görülmektedir. Bu sebepten dolayı zorunlu davranış ve boş zaman davranışlarını birbirlerinden ayırabilmek amacıyla dönemin içinde bulunduğu zamanın yapısı ve toplumsal ihtiyaçlarının doğru belirlenmesi gerekmektedir.

\section{Mekanın yapısı ve özellikleri}

Roman mekânsal açıdan ele alındığında, gerçekleştirilen boş zaman davranışlarının yaşanılan coğrafya ve toplumların mekânsal nitelikleriyle doğrudan ilişkili olduğu görülmektedir. Romanda anlatılan vaka zamanının büyük bir dilimi Ötüken ismindeki bozkır coğrafyasında, esaret döneminde ise Çin'in başkenti Siganfu'da geçmektedir. Farklı mekânlarda geçen olaylar; toplumların değişen boş zaman alışkanlıkları hakkında mukayese yapma imkânı tanımaktadır. Olayların geçtiği mekânlar yazar tarafından çok iyi tasvir edilmekte ve okuyucuya aktarılmaktadır.

Romanda bozkır, geniş çayırlara sahip uçsuz bucaksız bir mekân olarak tasvir edilmektedir. Aynı zamanda Türklerin özgürlüklerine olan düşkünlükleri, bozkır anlatımları üzerinden yapılmaktadır. Özellikle Çin'deki esaret yıllarında, özlem duyulan bir mekân olarak bozkır bu iki yönü ortaya koyması açısından önemlidir.

"Yamtarın içi sızladı. Ah Ötüken ah! Şimdi Türkeli’nde olsaydı yeşil yamaçlarda, sonsuz bozkırlarda nasıl at koşturur, dağlarda nasıl geyik avlardı. Bu Siganfu şehrinde ise tıpkı Çinliler gibi boğucu sokaklarda salına salına yürümekten, uyuşuk uyuşuk gezmekten başka yaptığı iş yoktu (s.355)." 
Mekânın özelliklerinin toplumların karakteristik özelliklerine ve boş zamanlarını değerlendirme alışkanlıklarına etkilerinin görülebileceği yukarıdaki bu satırlar, iki farklı toplum ve mekân açısından boş zaman davranışlarının kıyaslanmasına imkân tanımaktadır. Şehir hayatı Türkleri boğmakta ve aylaklığa itmektedir. Oysa Bozkır, ruhları gibi bedenlerini boşluğa salabilecekleri sonsuzluğu simgelemektedir.

Sert ve acımasız olan bozkırda yaşama devam etmek çok zordur ve yaşamak için sürekli olarak mücadele içerisinde olmak gerekmektedir. Türklere bozkırın bu özelliği sert mizaç ve sert bir karakter olarak yansımıştır (Bal, 2018). Bu özellik yalnızca bozkır erkeklerine has bir durum da değildir. Türklerin yaşadıkları coğrafya ve iklim özelliklerinin karakter yapılarına işlediği ve bunda cinsiyet ayrımının olmadığı net şekilde görülmektedir. Bozkır kadını ile erkeği arasında eşitlikçi bir profil romanın geneline hakimdir. Bozkır kadınının da erkeği kadar sert bir mizaç ve karaktere sahip olduğu (s.61) net şekilde görülmektedir.

Esaret dönemi anlatılarında Çin ile Bozkır arasındaki kıyaslama daha belirginleşmektedir. "Siganfu Çin'in başkenti. Bünyesinde atlar için ahırın da bulunduğu konuk evinde kalınıyor. Uçsuz bucaksız bozkıra alışmış olan Türkler için dar sokaklı Çin şehri ruhlarına sıkıntı veriyordu (s.252253)."

Yalnızca mekânsal açıdan bir kıyaslama değil aynı zamanda kültürel farklılıkların da toplumların yaşam tarzlarına ve toplumsal ahlâklarına olan etkisi çarpıcı bir örnekle anlatılmaktadır. On başı Üç oğul ile aslen Türk olan Çinli yaver Karakulan'ın karşılaşması (s.254-255) ve sonrasında yaşanılanlar, toplumların kendi kimliklerini kaybetme ya da koruma konusunda boş zaman davranışlarının önemine vurgu yapmaktadır. Dilini ve töresini unutan Karakulan Türklükten uzaklaşmış ve asimile olmuştur. Karakulan'ın davetine karşı koyamayan Üç Oğul, kışı Siganfu'da Karakulan'ın evinde geçirmeye ikna olmuştur. Evli olmadığı halde evinde çalgı çalıp şarkı söyleyip oyun oynayan birçok Çinli kadın bulunan Karakulan'ın yaşantısı Türklerden çok uzaktadır. Çinli şehir hayatı bozkır hayatından çok farklıdır. Türk töresine uymayan bu davranışlar Türklerin ahlâkını ve yaşamlarını olumsuz etkilemektedir. Evde çalgı çengili düzenlenen ziyafetler Türklerin eğlence kültürüne hiç benzememektedir.

Üç Oğul üzerinden kendi kimliklerinden ve töresinden uzaklaşan Türklerin, Türkler için olağan yaşam etkinliği olarak görülebilecek etkinlikleri bile gerçekleştiremedikleri çarpıcı bir örnekle vurgulanmaktadır:

"Birgün Türk beyleri Siganfu yöresindeki dağlarda ava gitmişlerdi. O gün Bögü Alp'in gözünden kaçmayan şey şu oldu: Üç Oğul bir tek av avlayamadı. Nişancılıkta sona kaldı. Kılıç oyununda yenildi. Güreşte iki gözü kör olan Gök Börü’ye alt oldu. At yarışında da geride kalıp ortalıktan çekildi."

$\mathrm{Bu}$ örnekte iki şey vurgulanmaktadır. Birincisi esaret altında dahi olsa Türklerin başka coğrafyalarda bile kendi kültürlerini korumak ve yaşatmak adına kendi törelerine has aktiviteleri sürdürdükleri, ikincisi de kendi kimliğinden uzaklaşan Türklerin hızla bunlardan uzaklaşıp kendine yabancılaştığıdır. Türklerin töresini, kimliği yansıtmaktadır. Birinden uzaklaşan diğerinden de uzaklaşmaktadır. Bunu çok iyi bilen Çinliler, Türkleri asimile etmek için onları Çin'in farklı noktalarına göndermek ve törelerinden uzaklaştırmak istemektedirler. Gökalp (2017: 21)'in ifade ettiği şekliye "devlet yahut ülke terk edilebilir, hars (kültür) terk edilmez" manasına gelen "il bırakılır, töre bırakılmaz” Türk atasözü bu durumu açıklamaktadır.

Esaret altına alındıklarında, Çinliler Türkleri kendi içlerine alarak onları değiştirmek için çabalasalar da başarılı olamazlar. Türkler şehir hayatına alışamazlar. Siganfu'ya getirilen Türkler şehir hayatına adapte olamamaktadırlar. Özgürlüklerine düşkünlükleri evlerin farklılıklarında da kendisini göstermektedir. 
Siganfu'da boş zaman değerlendirme aktiviteleri için özel olarak tasarlanmış alanlardan söz edilmektedir. Oyun bahçesi ismi verilen bu alanlarla ilgili:

"Bir aralık geniş bir alana geldiğini, işittiği çalgı seslerinden anladı. Boyalı tahtalarla çevrilmiş bir bahçenin kapısında Çinli çalgıcılar çalgı çalıyor, acayip kılıklı bir Çinli bağırarak bir şeyler söylüyordu. Çinlilerin bayramı diye düşündü (s.355)."

"Burası iyi bir kazanç yeri. Herkes hünerini gösterip akça alıyor. Çinliler cambazlık yapıyor, Türkler de güreşe çıkıyor (s.357)."

hem bahçenin tasarımı hem de yapılan etkinliklerle ilgili bilgiler yer almaktadır. Romanda eğlence bahçesi olarak ifade edilen alan, çevresine Çinlilerin izleyici olarak oturdukları, orta kısmı sahne olarak planlanmış büyük bir bahçedir. Ortasında iki direğin arasına gerilmiş bir ip bulunmakta ve ipin üzerinde Çinliler hüner olarak cambazlık gösterileri sergilemektedir. Aynı zamanda bahis oyunlarının da oynandığı bir alan olması sebebiyle kazanç yeri olarak görülmektedir. Kültürel etkileşim oyun bahçelerinde gerçekleştirilen etkinlikler üzerinde de etkili olmaktadır. Çinlilerin cambazlık gibi gerçekleştirdikleri hüner gösterileri Türkler tarafından uygun bulunmadığından, Türkler için güreş oyunları sergilenmektedir.

\section{Boş zaman değerlendirme ve oyun etkinlikleri}

Boş zaman değerlendirme etkinlikleri açısından zamanın özellikleri ve mekânsal nitelikler belirleyici bir rol üstlenmektedir. Zamansal ve mekânsal uygunluk hem etkinliklerin içeriğini hem de etkinlik çeşitliliğini etkilemektedir. Bunun yanı sıra iklim, doğal yaşam, toplumsal alışkanlıklar ve kültürün de boş zaman değerlendirme etkinlikleri üzerinde etkisi önemli düzeydedir. Romanda yaşanılan coğrafya ve mekân hakkında bilgilendirmelerden sonra boş zaman ve oyun figürleri rekreasyon yaklaşımıyla incelenmiştir.

\section{Kağanlık kutlaması}

Kağanın; kineş (meşveret) için kurultay toplamasının dışında, önemli olaylar ve kazanılan zaferler için kutlamalar düzenlediği görülmektedir. Başa geçen kişinin "kağanlık kutlaması" bu kutlamaların en önemlilerindendir. Bu kutlama hem budunda saygı uyandırmak hem de kağanın gücünü göstermesi gibi görevler üstlenmektedir. Bağatur Şad'ın başa geçerek "Kara Kağan" ismini alması üzerine yapılan "Kağanlık Kutlaması" şöyle tasvir edilmektedir:

"On gün sonra Ötüken'de Bağatur Şad'ın kağanlığı kutlanıyordu. Bağatur Şad artık Kara Kağan adını almıştı. Yüce otağı bezenmiş, süslü bir taht kurulmuştu. Davullar çalınıyor, borular ötüyor, kımızlar sunuluyordu (s.34), yeni kağanın otağı önünde toplanan binlerce kişi bol bol kımız içip esridikleri halde büyük bir sessizlik içinde idiler. Yalnız davulların, boruların, zillerin sesleri ötükeni dolduruyordu. Gün kararıncaya değin eğlenti yapılacaktı. Güreşçiler güreşecek, bahadırlar dövüşecek, nişancılar ok atacak, biniciler yarışacaktı, kılıç oyunları oynanacaktı (s.36)."

Kağan adına yapılan kutlamalarda yapılan etkinlikler, dönemin boş zaman ve oyun figürleri olarak dikkat çekmektedir. Ayrıca kağanlık kutlamalarında ödüllü yarışmaların da yapıldığı görülmektedir. Benzer şekilde Kağan; kılıç oyununda kendisinden rütbece üstün olan Tunga Tegin'le denk olan Yüzbaşı İşbara Alp'i binbaşılığa yükseltmiştir. Kağan'ın izlediği oyunlar yalnızca bir boş zaman değerlendirme etkinliği değil aynı zamanda kişilerin kendilerini ispat etmeleri için bir firsat niteliğindedir. Kağan kutlaması için yapılan kutlamaların günlerce sürdüğü ve türlü eğlence ile oyun etkinlikleri yapıldığı görülmektedir.

Kazanılan zaferler sonrasında kutlamalar yapılmaktadır. "Büyük akın sonrası galip gelen İlteriş Kağan bugüne kadar yaptığı savaşların en büyüğünü kazanmıştı. Şimdi beğlere ulu bir şölen veriyordu. Her yanda davullar çalınıyor, kımızlar içiliyor, gençler güreşiyor, yiğitler at yarıştırıyordu (s.593).” Kutlamaların her ne sebeple yapılırsa yapılsın, süre ve etkinlik çeşitliliği bakımından farklı olsa da içerik olarak benzer oyunların gerçekleştirilmektedir. 
Kağanlık kutlaması ve zaferler dışında, Kağanların kendilerine gönderilen elçiler için eğlence amaçlı "toy" düzenledikleri; ayrıca toy dışında kağanın ziyafet masalarının kurulduğu "ş̧̈len" ismi (s.204) verilen daha büyük bir eğlence tertip ettikleri görülmektedir.

İzgi (1977) Çin kaynaklarından derlediği çalışmasında, Türklerin hayatında önemli bir yere sahip olan "toy"ların, tahta çıkma ve elçi kabulü dışında doğum, bey oğlunun ilk avı ve bir felaketten kurtulma gibi nedenlerle de düzenlendiğini ifade etmektedir. Müzik, kımız, ziyafetler gibi toy ve eğlencelerin bilinen etkinliklerine ek olarak aktörlerin gece oynadığı bir oyundan bahsetmektedir.

$\mathrm{Bu}$ toy ve şölenlerin süre bakımından Kağanlık Kutlaması kadar olmasa da yapılan etkinlikler benzerlik göstermektedir. Kağan'ın kendisinde gönderilen elçiler ile kendi budunu içinden seçtiği erler arasında yapılan kılıç oyunu, nişancılık, güreş ve at yarışı gibi yarışma türündeki etkinlikler, yarışanlar için kendi budunlarını ve kağanlarını yüceltmek için yaptıkları bir hüner gösterisine dönüşmektedir. Torkildsen (1991:66-67) rekreasyon'un birey ve toplum için bir değer olduğunu savunmaktadır. Rekreasyon, bireyin ve toplumun "iyiliği" için yüksek ahlâki ve sosyal değerleri içermektedir. Özellikle çocukluk dönemlerinde oynanan oyunlar çocuğun gelişimine katk1 sağlayan, onları özgür ve mutlu hissettiren anlamlı davranış biçimlerindendir. Olumlu kimlik gelişimi, yaratıc1lık, dengeli rekabet, karakter, zihinsel kapasite, bireyin onuru, fiziksel koşullanma, sosyalleşme ve sorunlarla başa çıkabilme gibi bireye değer katıcı, onun gelişimine ve öz zenginliğine olanak sağlamaktadır.

\section{Müzik ve eğlence}

Bozkır hayatında ve özellikle kutlamalarda müziğin önemli bir yeri bulunmaktadır. Roman içerisinde kutlamalarda çalınan davullardan, borulardan ve ozanların çaldıkları kopuz adlı sazdan bahsedilmektedir. Müziğin önemi dönemin müzisyenleri olarak ifade edilebilecek ozanlara gösterilen hürmetten de anlaşılmaktadır. Romanda Kara Ozan, Çuçu, Dokuz Oğuz Ozanı ve isimleri söylenmeyen birkaç ozandan daha söz edilmektedir. Kara Kağan'ın 'Ozanların sözü kutludur, kesilemez (s.54)" buyruğu ozanlara gösterilen saygının ve önemin bir göstergesidir.

Ayrıca Göktürklerde boş zamanın sosyal sınıfın sembolü olmadığının en güzel örneği, Kara Kağan'ın kopuzunu çalması ve ardından deyişler okuması ile farklı statüdeki kişilerin aynı etkinlik içerisinde buluşmasıdır.

Türk folklorunda mühim bir yere sahip olan kopuz; destanlar, kahramanlık menkıbeleri, aşk türküleri, acı tatlı hatıralar ve toplumsal olayların dile getirilmesinde kullanılan bir çalgıdır (Kafesoğlu, 2018: 328). Kara Ozan'ın söylediği deyişe (s.28) ordunun duygulanarak hep bir ağızdan eşlik etmesi ve Çuluk Kağan'ın ölümünün konu edinilmesi dikkat çekicidir.

Romanda günümüz Aşık atışmalarına benzer Ozan atışmalarına (s.53) rastlanmaktadır. Toylarda bütün yarışlar, koşular ve oyunlar bittikten sonra ozanların atışmalarına geçilmektedir. Karşılıklı sözlerle yapılan ozan atışmalarının Göktürkler döneminde yerel halkın önemli eğlence türlerinden olduğu söylenebilir.

Ozanların yalnızca toy, düğün, kutlama ve şölenlerde değil, gündelik yaşamda, seyahatlerde mola sırasında ve hatta savaşlarda kopuz çalıp deyişler söylediği görülmektedir. Ozan atışmasına dönüşen kopuz çalma ve söyleme toplumun içinde bulunduğu sosyal olayları (s.140-142) konu edinmektedir.

Ozanların çaldığı kopuz ve söyledikleri deyişlerin toplumsal bütünleşmeyi sağlayan dönemin sosyal rekreasyon aktivitesi olduğu görülmektedir. "Akın sözü üstüne büsbütün coşan Türkler, hep birden oynamaya başlamışlardı. Şimdi hem Çuçu, hem de öteki Ozan yalnız kopuz çalıyorlar, alışveriş evindeki bütün Göktürkler de hızlı adımlarla bir ileri, bir geri giderek ve birden çömelip birden kalkarak Türk raksı yapıyorlardı (s. 142)." Türk raksı diye ifade edilen bir oyun türünün hareketleri tasvir edilmektedir. Ayrıca Türk raksı ve oyunları ile Türklerin birlik oluşları ve 
kaynaşmaları, rekreasyonun sağladığı sosyal faydalardan toplumsal dayanışma ve bütünleşmenin sağlanması işlevi şu ifadelerle anlatılmaktadır:

"Uygun adımlarla yürüyüşleri gitgide korkunçlaşıyordu. Şimdi orada tek bir yürek vardı: Senlik, benlik silinmiş, bölünmez bir varlık çıkmıştı. Kancık Çin’e karşı öç duygusuyla yanan bu tek gövde savaşmak, boğuşmak için deli oluyordu (s.143)."

Benzer şekilde "Ozanların sözünde ve kopuzunda büyü mü vardı bilinmez. Fakat onlar çalıp söylerken Ötüken tek yürek gibi çarpardı (s.277-288).” Bireye ve topluma bir değer olarak rekreasyon yaklaşımına göre toplumsal rekreasyon, sosyal birlikteliğin sağlanmasına ve korunmasına aracılık etmektedir ve toplumsal rekreasyonun geliştirilmesi sosyal katılıma bağımlıdır (Torkildsen, 1991:67). Sosyal katılıma bağlı olarak sağlanan toplumsal fayda bu örnekte açık bir şekilde görülmektedir.

Ozanlar yalnızca toy, şölen, kutlama ve eğlencelerde ortaya çıkan bir figür olmanın çok ötesindedir. Gökalp (2017: 76) ozanların, hem kâhin, hem şair hem sihirbaz olarak görülen ruhaniler olduğunu; şölenlerde kopuz çalarak Oğuzname'yi okuduklarını söylemektedir. Bozkırın karakteristik özellikleri ozanlar üzerinde de etkisini göstermekte, ozanlar aynı zamanda savaşçı kimliğe sahip olan erlere dönüşebilmektedir. Romanın "Bozkurtlar Diriliyor" bölümünde (s.457) ozanların yalnızca eğlence ve oyun kültürünün bir öğesi olmadığı, aynı zamanda savaş ve kahramanlık duygularının açığa çıkarılması için üstlendikleri görevlerinin de bulunduğu görülmektedir. Toy, şenlik, eğlence ve yolculuk molalarının dinlendirici ve eğlendirici işlevlerinin dışında savaş anlarının askerleri motive edici bir unsuru olduğu söylenebilir. Ozanların savaş zamanlarında söylediği kahramanlık türküleri ve çalınan boru ile davulların, mehteranın ilk şekilleri olarak kabul edilebilecek askeri mızıka ya da bandonun bu dönemdeki örneği kabul edilmektedir (Kafesoğlu, 2018: 328).

Türklerin özel günlerde şölen yaptıklarına rastlanmaktadır. Yukarıda bahsi geçen kutlama amaçlarının dışında doğa olayları, yeni yılın kutlanması ve bayramlar gibi özel günlerde yapılan kutlamalar görülmektedir. Nevruz'a atıf yapılan yeni yıl kutlaması romanda şu şekilde geçmektedir: "Bozkıra yeni bir bahar gelmişti. Ağaçlık bir düzlükte tören vardı (s.484)." Baharın gelişinin ve törenin aynı şekilde ifade edilmesi, Türklerin yeni yılı ve bahar bayramına yapılan bir atıf olarak dikkat çekmektedir. Aynı zamanda "Göktürk devletinin yeniden kurulması (s.485)" bu törende açıklanmaktadır. "Davullar çalınıyor, kımızlar içiliyor, bir ozan deyiş söylüyordu (s.485), çerinin sevinç haykırışları, kılıç oyunları ve güreşler (s.487)" törenin anlatıldığı bölümdeki oyun örnekleri olarak görülmektedir.

Rekreasyon yaklaşımlarından "yeniden yaratma kuramı"na göre; insanlarda oluşan yoğun stres ve gerilim oyun yoluyla azalmakta ve birey rahatlamaktadır. Bireyin sağllk ve gücünü yeniden kazanabilmesi için başvurduğu eylemlerin başında oyun gelmektedir (Tekin, 2016: 57; Hazar, 2014: 25). Taçam üzerinden verilen örnek ile (s.599) yapılan gezintiler, avlanma, yarışlar, güreş ve kopuzla yapılan müzikli eğlence türleri ile bireylerin stres ve sıkıntıdan uzaklaşması, psikolojik açıdan rahatlamasına gönderme yapılmaktadır.

\section{Oyun aktiviteleri ve kuralları}

Romanda oğlak kapma, okçuluk (nişancılık), kılıç oyunu, güreş, at yarışı, yemek yeme yarışı gibi pek çok oyun örnekleri yer almaktadır. Bu oyunlarla ilgili en dikkat çekici durum, oyunların kurallar dâhilinde oynanması ve oyun boyunca ortaya konulan kuralların hiçbir şekilde bozulmamasıdır. Kurallar dâhilinde oynanan oyunlar kağan ya da rütbece üst olan kişi tarafından başlatılmaktadır.

$\mathrm{Bu}$ oyunlar aynı zamanda elçi gönderilen yerlerde bağlı bulunulan kağanlığı temsil etmek amaciyla yapılan oyun türlerindendir. “Tüng Yabgu Kağan'ın otağının önünde iki kağanın bahadırları karşılaştılar. Dede Korkut, Tanrı’ya yakarış yaptıktan sonra oyunlara başlandı (s.197), 
Batı Kağanı katında ok atılsa, kılıç oyunu olsa, at yarıştırılsa, güreş yapılsa (s.187)" ifadelerinden anlaşılacağı üzere; kılıç oyunu, ok atma, güreş, at yarışları gibi oyunların Batı Kağanı'nın otağının önünde oynandığg görülmektedir. Bu oyunlardan at yarışları ilgili kural "otağı̆ önünden dört beş bin adım ilerde dikilmiş tuğları kapıp yeniden otağın önüne gelmek (s.199-200)" ş̧eklinde açıklanmaktadır.

Elçi karşılamalarında yapılan törenlerde de kurallı oyun örnekleri görülmektedir (s.533). Aynı zamanda bu oyunlarda başarılı olan erler, kendilerini ispat etmiş ve Kağan'ın gözüne girmiş sayilmaktadır.

Romanda bahsi geçen oyun örneklerinden en dikkat çekici olanı şüphesiz "Oğlak kapma oyunudur". Kökböri adı verilen geleneksel Türk oyununu andıran bu oyun yalnızca bir oyun olmanın ötesinde Türk Töresinin uygulamalı bir örneğidir. Türk Töresine göre evleneceği kiş̧iyi belirlemek adına Türk kızının (Almıla) "oğlak kapma" adı verilen bir oyunu oynama hakkı bulunmaktadır. Oyun kurallarına göre; kızla evlenmek isteyen atlılar rütbe sırasına göre saf halinde alana dizilmektedir. Kız kesilmiş bir oğlakla alana gelir ve saf halinde dizilmiş atlıların yirmi otuz adım kadar uzağından önlerinden geçer. Kız dokuz defa atlıların önünden geçtikten sonra atını koşar ve davul sesi ile saf halindeki atlılar kızın elinden oğlağı almak için atlarını sürerler. Oğlağı kapan erkek ile kız nişanlanmış (s.221) sayılmaktadır. Oyun sonunda kazanan için bütün herkes uğur ve kut dilerler. Bu oyunda bir erkeğin, kendisini istemeyen kızın elinden oğlağı kapmasının çok güç olduğu da herkes tarafından bilinmektedir. Çünkü kızın istemediği erkeğin yüzüne kırbaçla vurma hakkı bulunmaktadır (s.216).

Oyun kendi içerisinde bir düzene sahiptir. Her oyunun kendine has bir düzeni bulunmaktadır ve bu düzenin kaybolması oyunun özelliğinin kalmamasına neden olmaktadır (Ardahan, 2016: 122). Kurallarına uymanın önemi gene bu oyunda görülmektedir. Oğlak kapma oyununda Çinli'nin yaptığ hile ile davul erken çalmış ve Çin'li rakiplerine göre erken davranarak avantaj sağlamaya çalışmıştır. Oyun kuralının bozulması "artık düzen, töre, yasa kalmamıştı (s.219)" şeklinde ifade edilerek, sosyal olaylarda ortaya konulan oyun kurallarının bozulmasının, toplumun düzenin bozulması olarak görülmesi anlamına geldiği vurgulanmıştır. Oyun kurallarına uymayanlar ya da kuralları çiğneyenler "oyunbozan" olarak toplumun düzenini bozmaktadır.

Hüizinga oyunun kültürden önce ortaya çıkan bir kavram olduğunu, çeşitli kültürlerden çıkma ya da rastlantı sonucu değil, aksine çeşitli kültür biçimlerinin doğuşunda yer alan başlıca etkenlerden olduğunu ifade etmektedir. Oyunun içinde yer alan oyuncular, oyun sayesinde gizli bir bağ ile birleşmekte ve bu sayede toplumsal öbekleşmenin sağlanmasına neden olmaktadır (Hüizinga, 1995). Oyunu bir kültür unsuru olarak gören yaklaşım, Hüizinga'nın bu anlayışından doğmuştur.

Oyunlar toplumun işlevini yansitan örneklerdir. Bu yüzden oyunun özünü yitirmesi; toplumun özünü yitirmesini, zayıflığını ve mevcut bozulmuşluğunu yansıtan bir ayna olduğu kabul edilmektedir (Tekin, 2016: 61; Caillois, 1961: 21). Türkler kurallara nizami uyan bir portre çizmektedirler. Hile ve oyunbozanlık yapmayan, kurallara uymanın "töreye uymak" olduğunu bilen Türkler ile Çinliler arasında kıyas yapma imkânı tanıyan, aynı zamanda milletlerin karakterleri hakkında bilgiler veren sosyal olaylara dönüşmektedir. "Çalkara güreş tutkunu biriydi. Güreşmezse hasta olurdu. Bu yüzden kış olunca tepelere, dağlara çıkıp ayılarla güreşirdi. Hem de mızıkçılık etmemek için yanına pusat almaz, kemerindeki bıçağı da ayıların mızıkçıllğına karşı ihtiyat olarak tutardı (s.531). Bazen güreşecek ayı bulamazsa atıyla güreşirdi (s.532)." Mızıkçılık kavramının geçtiği bu örnek olayda; bir Türkün, bir ayıya karşı dahi oyun kurallarını bozmadığı görülmektedir.

Kağan Kutlamasında sergilenen oyun türleri kurallı oyunlara verilebilecek örneklerdendir. Kağanlık Kutlamasında oynanan Nişancılık oyun kuralları romanda şu şekilde anlatılmaktadır: "Kağanın oturduğu yerin sol açı̆̆ında gez tahtası yükseliyor, üstünde karaya boyanmış yuvarlaklar çok iyi seçiliyordu. Bu yuvarlakların sayısı dörttü. Illk atıcılık bu dört yuvarlağı yukarıdan aşağı sıra ile vurmak ile başlayacaktı, beceremeyenler alandan çekileceklerdir (s.48)." Nişancılık oyunu da 
kendi içerisinde kurallar dâhilinde gerçekleştirilmektedir. Oyunu kurallarına göre oynamayan ya da sıralamaya uymayan kişi elenmektedir. Oyunda başarısız olanlar eleniyor, başarılı olanlar daha da uzaklaşan mesafeden atışlarını yapıyordu. Kalan son iki kişi için oyun daha da farklılaşmıştı. Havaya atılan yumurtalar inmeye başlamadan önce vurulacaklard1. Bu oyunda da yenişemeyince en son kenarları birer arşın kadar görünen iki büyük tahta getirildi. Ellişer okla tahtaya "Türk" yazılacaktı ve ilk kim yazıyı bitirirse o kazanacaktı (s.52)." Oyun örneklerinde kuralların kolaydan zora doğru ilerlediği görülmektedir.

Romanda yer alan oyun örneklerinin çoğu yetişkinler için uygulanan oyunlardır. Oyun kuramları içerisinde "yaşama hazırlık (öncül deneme) kuramı" bireyin oyun aracılığıyla daha sonraki yaşamına hazırlandığını savunmaktadır. Bireyler oyun yoluyla hayatın ileri dönemlerine ilişkin eylemlerin deneyimlerini yaparak gelecekteki yaşamlarına hazırlanmaktadırlar (Tekin, 2016: 56; Tokuz, 2011: 9). Dolayısıyla çocuklar, içinde yaşadıkları toplumsal yapının değer olarak gördüğü "er" olmak anlamına gelen "alp"liği elde edebilmesi için yetişkinlerin yaptıkları oyunları yaparak gelecek yaşamlarına hazırlanmaktadırlar. Nitekim Eski Türk Yazıtlarına göre "beylik duygusu+insan sevgisi+gerçekçilik şeklinde özetlenebilecek olan eski Türk düşüncesinin esaslarını ahlâk prensibi yapmış, yani hayatında düstur edinmiş insana eski Türkçede "Alp" denilmektedir (Kafesoğlu, 2018: 332). Ancak romanda çocuklarla ilgili bahsin geçtiği yerlerde, çocukların bozkırda serbestçe oynadıkları, bu oyunların yetişkinlik dönemine hazırlık oyunları olmakla birlikte farklı oyun türlerini de içerdikleri görülmektedir. Burada güreş, kılıç oyunu, okçuluk ve at yarışı dışında "taş yarıştırma" oyunu yalnızca çocuk oyunu olarak romanda geçmektedir.

Türklerde çocuk oyunları bir boş zaman değerlendirme etkinliği olmanın çok ötesinde eğitimlerinin bir parçası olarak görülmektedir. Gökalp (2019: 21) çocuk terbiyesinde bir takım derslerin oyun tarzında verildiğinin altını çizmektedir. Oyun ve kültür arasında sıkı bir ilişki bulunmaktadır. Oyun, çocuğu içinde yaşadığı kültüre hazırlamak için eşsiz bir etkinlik türüdür. Vygotsky (1967), çocuğa kendi kültürüne ait değerleri öğretmesi noktasında oyunun katk1 sağladığını savunmaktadır. Romanda geçen "Koca dedesi ona daha ilk binicilik derslerini verirken: -Türk ata bindi mi gözü atasını bile görmemeli. Oğul! Gerektiğinde kişi canını bile verir ama at, avrat, pusat; bu üçü verilmez! demişti (s.169), dedesi ona ok atmasını, kılıç ve kargı kullanmasını, ata binmesini, güreşmesini öğretmişti (s.170), Yüz başı Yağmur kopuz çalıp deyiş söylemesini babasından öğrenmişti (s.278)" kısımlar, oyun yoluyla çocuklara Türk töresinin "öğütlerle" aktarılmasında "sosyo-kültürel gelişim kuramı"nın örneklerindendir. Çetin (2010) Türk-İslam kültürünün önemli eserlerinden olan Kutadgu Bilig'de sosyal kültürün babadan oğula aktarılmasında ve kültürün devamının sağlanmasında ögütlere dikkat çekmektedir.

Aynı zamanda oyun yaklaşımlarından olan "taklit ve tekrar (yineleme-rekapitülasyon) kuramı"na göre oyun, bireyin içinde yaşadığı kültürün bir özeti ve yansıması olarak ifade edilmektedir. Bireyler oynadıkları oyunlar sayesinde atalarının geçmiş yaşam tarzlarını canlandırmaktadır. Diğer bir ifadeyle, bireyin oyunu içgüdüsel olarak gelişmekte ve bireyler oyun içerisinde atalarının geçirdiği ruhsal aşamaları tekrar yaşamaktadırlar (Öztürk Serter, 2018: 22-23).

Türklerin esaret döneminde Siganfu'da bulunan bir oyun bahçesinde "yemek yeme yarışı" adında bir oyundan bahsedilmektedir. Bahis oyunlarının da oynandığı eğlence bahçesi, Ötüken'de oynanan oyunlar ve yarışmalar neticesinde verilen ödüllerden farklı olarak "kumar oyunlarına" benzer bir niteliktedir. Romanın farklı yerlerinde Çinliler için "kumar oynama" (s.59) davranışlarında bulundukları anlatılmaktadır. Kumar Çinliler için bir boş zaman davranışı olarak görülmektedir. Türkler içinse "Karşılığında birinciye altın akça, ikinciye gümüş akça ödülü olan at yarışı (s.121)." gibi ödüllü yarışmalardan bahsedilmekte, kumar niteliğinde oynanan oyunlar yer almamaktadır. Türklerin kumar benzeri bahis oyunlarına esaret dönemlerinde Çin topraklarında katıldıkları görülse de verilen örnekte yemek yeme yarışmasına katılan Yamtar'ın para kazanmak adına değil yarışmayı kazanmak adına oyuna katıldı̆̆ı görülmektedir. 
Bir boş zaman davranışının rekreasyona dönüşmesi için en önemli motivasyon kaynağı, bireyin haz ve doyumunu esas alan "içsel motivasyon" unsurlarıdır. Bunun dışında ödül ve rekreasyonun sağladığı faydalara odaklı (fiziksel, sosyal, bilişsel ve psikolojik faydalar gibi) "dışsal motivasyon" unsurları da bireyin katılımını etkileyen etmenlerdendir. Her iki motivasyon unsurlarını içeren rekreasyon etkinliği ideal etkinlik olarak ifade edilmektedir (Leitner \& Leitner, 2012: 14). Yamtar burada oyunun içsel motivasyon unsurlarına yoğunlaşmış, dışsal motivasyon unsurlarını görmezden gelmiştir. Yamtarın yalnızca dışsal ödüllere odaklanması gerçekleştirdiği etkinliği bir "a tipik" boş zaman davranışına dönüştürebilecekken, tutumu sayesinde bir rekreatif aktivite olmasını sağlamıştır.

\section{Kültürel farklılıklar}

Göktürkler ve Çinliler dışında; Batı Türkleri, Dokuz Oğuzlar, Suğdaklar, Kıtaylar ve Sırtarduşlar'dan bahsedilmektedir. Batı Türkleri, Dokuz Oğuzlar ve Sırtarduşlar, Türk oldukları için aynı kültüre ait olup törece aynı kuralları uygulamaktadırlar. Suğdaklar ve Kıtaylar hakkında ise ayrıntılı bilgi bulunmamaktadır. Bu sebepten dolayı boş zaman ve oyun figürleri bağlamında, coğrafya ve kültür açısından yalnızca Çinliler ile karşılaştırma yapmak mümkün olmaktadır.

Türklerin savaşçı yapıları, boş zaman ve oyun etkinliklerinde kendisini göstermektedir. Sahnelenen ve canlandırılan her etkinliğin "oyun" olarak kabul edildiği Türklerde, dini bir ritüel ve savaşa hazırlık amacıyla gerçekleştirilen oyunlarla birlikte yalnızca eğlence ve hoş̧̧a vakit geçirmek maksatlı boş zamanları değerlendirme etkinliklerinden de söz edilmektedir (Çetiner, 2019: 112). Romanda daha çok; okçuluk, güreş, kılıç oyunları, atla oynanan oyunlar gibi güce ve kondisyona dayalı oyun örneklerinin ağırlıklı olduğu görülmektedir. Akına hazırlık adına yapılan savaş talimlerinin dışında güç ve kondisyon odaklı bu oyun türlerine; toy, şölen, kutlama ve eğlencelerde sıkça rastlanılmaktadır. Coğrafya bakımından şehir hayatı yaşayan Çinlilerin, uçsuz bozkırlarda yaşayan Türklere göre boş zaman aktiviteleri değişim göstermektedir. Çin şehirlerinde daha çok oyun bahçeleri boş zaman değerlendirme alanları olarak görülmektedir. $\mathrm{Bu}$ alanlarda Türklerin gerçekleştirdikleri "okçuluk, güreş, kılıç oyunları, atla oynanan oyunlar" gibi oyunlar yerine, cambazlık gibi farklı hüner gösterileri ile kumar gibi istenmeyen boş zaman davranışlarının sergilendiği görülmektedir. Bahçede görevli kişinin dikkat çekici kıyafetler giyerek bahçeye davetlerde bulunduğu, çalgıcıların çalgı çaldığı bir eğlence ve bahis oyunlarının oynandığı bir "kazanç yeri" niteliğindedir. $\mathrm{Bu}$ oyunlar seyircilerin çevrelediği sahne tarzı bir alanda sergilenmektedir. Türklerin Siganfu'da esir edilmelerinin ardından bu bahçede oynanan etkinlik türleri de farklılaşmıştır. Çinlilerin oynadığı bu oyunları kendilerine yakıştıramayan Türkler için güreş gibi etkinlikler yapılmaya başlanmıştır. Kültürel etkileşim ve oyun türlerinin belirlenmesinde kültürün etkisinin görülmesi açısından Türklerden önce ve sonra oyun bahçelerindeki etkinlik türlerinin farklılaşması örnek olarak verilebilir.

Çin kağanının verdiği kutlama ve şölenler Türklerin "Kağan Kutlaması”na göre farklılık göstermektedir. Türklerde oyun örneklerinin sergilendiği, yarışmaların yapıldığı, Ozanların kopuzlarla deyişler söylediği ve boru ile davulların çalındığı eğlenceler düzenlenmektedir. Türklerde boş zaman; yalnızca belirli ve seçkin bir sınıfın kullandığı "sosyal sınıfın bir sembolü" değil, bütün budunun katıldığ 1 etkinlikleri içeren kutlamalardır. Çinlilerde ise Çin Kağanı'nın verdiği şölen şu cümlelerle anlatılmaktadır: "Şölene elli kişi gelmişti. Renkli fenerlerle süslenen bahçede, çalgıcıların ezgileri arasında yemeğe başlandı. Aralarında nazırlar ve kumandanlar bulunan konuklar, uşakların getirdikleri yemekleri yiyorlar, keskin sücü ile keyifleniyorlar, güzel yemişlerle içlerini serinletiyorlardı (s.563)." Konukların nazırlar ve kumandanlardan oluştuğu, hizmet eden kişiler için "uşak" tabirinin kullanılması, Çinlilerde sınıfsal ayrımın daha keskin bir şekilde oluştuğunu ve kutlamaların belli bir sınıftan kişilerin katıldığı etkinler olduğu vurgusu yapılmaktadır.

Çinlilerin kumar oynaması ile ilgili "Şen King, yoldaşları olan üç çin subayını çağırıyor, onlarla konuşuyor, kumar oynuyor, kımız yahut sücü içiyor (s.59) ve Fu-Lin Ticaretle Türkleri 
Kumarla da Çinlileri soyuyordu (s.73)" ifadeleri görülmektedir. Türklerde ise kumar ya da bahis oyunları görülmemekte, yalnızca ödüllü oyunlara yer verilmektedir.

Çinlilerle karşılıklı oynanan oyunlarda, Türkler oyun kurallarına uymak konusunda hassas davranırken, Çinliler hile yoluna başvurmaktadırlar. "Oğlak Kapma" oyununda oyunun başlama ritüelleri yerine getirilmeden oyuna başlanması ve bu hilenin Çinli tarafından yapılması buna örnek olarak gösterilebilir.

\section{Sonuç ve değerlendirme}

Türklerin boş zamanlarında katıldıkları rekreasyon aktiviteleri onların kültürlerinin bir parçasıdır. Göktürkler dönemi ve bozkır hayatını tarihi gerçekler ışığında titizlikle ele alan Atsız, dönemin sosyal zaman unsurları olan inançları, gelenek ve görenekleri, eğlence ve oyun etkinlikleri hakkında bilgiler vermektedir. Sosyal zaman öğeleri açısından incelenen roman, belirtilen hususlardan yalnızca boş zaman alışkanlıkları ile oyun ve eğlence kültürleri açısından irdelenmiştir. Romandaki sosyal zaman unsurları, boş zaman ve oyun kuramları perspektifinde değerlendirilerek dönemin oyun ve eğlence kültürü belirlenmiştir.

Romanda anlatılan zaman kullanım amacına göre irdelendiğinde; zorunlu faaliyetler için gerekli olan zaman dilimleri içerisinde temel fizyolojik ihtiyaçların giderilmesi ile dönemin temel çalışma zamanını oluşturan faaliyetlerin akınlar, tarım ve hayvancılık, avcılık, ticaret ve mübadele, demircilik gibi farklı meslek gruplarının iştigallerinden oluştuğu görülmektedir. Bunun yanı sıra ailesel ve toplumsal sorumlulukların yerine getirildiği faaliyetler de zorunlu davranışlar için gerekli olan zaman dilimi içerisindedir. Toplumsal gerekler göz önünde bulundurulduğunda, zorunlu zaman ve boş zaman arasında net bir ayrımdan söz etmek mümkün olamamaktadır. Bazı durumlarda bir boş zaman davranışı olarak yapılan "avcılık" kıtlık ya da açlık zamanlarında zorunlu davranışa dönüşmektedir. Benzer şekilde akın ya da savaş hazırlığı olarak gerçekleştirilen kılıç, ok talimleri ile güreş ve at binme faaliyetleri bir zorunlu davranış; toy, tören ve şölenlerde yapılanlar ise bir boş zaman davranışı olarak görülmektedir. $\mathrm{Bu}$ sebepten dolayı zorunlu davranış ve boş zaman davranışlarını birbirlerinden ayırabilmek amacıyla dönemin içinde bulunduğu zamanın yapısı ve toplumsal ihtiyaçlarının doğru belirlenmesi gerekmektedir.

Mekânsal açıdan boş zaman davranışları incelendiğinde; mekânın niteliksel özelliklerinin boş zaman değerlendirme etkinlikleri ve oyun türleri üzerinde etkili olduğu görülmektedir. Türklerin yaşadıkları coğrafya ve iklim şartları, onların boş zaman değerlendirme kültürlerini doğrudan etkilemektedir. Gündelik yaşamda kullandıkları araç ve gereçler, oyun türlerini ve oyunda kullandıkları aletlerin neler olacağı yönündeki belirleyici hususlardandır. Bu yüzden oyun türleri içerisinde okçuluk, kılıç oyunu, güreş, atla oynanan oyunlar en belirgin oyun örnekleri olarak tespit edilmiştir.

Türklerin özgürlük dönemlerindeki coğrafi mekânı bozkırın içerisindeki Ötüken, esaret dönemlerindeki coğrafi mekânı ise Çin'in başkenti Siganfu şehridir. Bozkır hayatında gerçekleştirilen boş zaman etkinlikleri ile şehir hayatındakiler farklılık göstermekte, romanda kırsal ve kentsel rekreasyon türleri açısından farklılıklar göze çarpmaktadır.

Türklerde Kağanlık kutlaması, toy, şölen, kutlama adını verdikleri pek çok eğlence türü bulunmaktadır. Zafer kazandıktan sonra, kağan değiştiğinde, bahar geldiğinde, önemli akınlar öncesinde ve elçiler geldiğinde bu tarz eğlence türleri düzenlenmektedir. Bu kutlamalarda ayrıca kı1ıç oyunları, nişancılık, okçuluk, güreş, at yarışları ve oyunları ile ödüllü yarışmalar yapılmaktadır. Bir boş zaman değerlendirme etkinliği olmakla birlikte kağanın önünde ve toplumun içerisinde statü ve değer kazanmak adına yapılan etkinlikler olduğu da görülmektedir. Türklerde boş zaman davranışları bireye ve topluma bir değer sunmaktadır.

Eğlence türlerinde ve Türklerin bozkır hayatında ozanların önemli bir yeri bulunmaktadır. Ozanlar yalnızca eğlence ve oyun kültürünün bir öğesi değil, aynı zamanda savaş ve kahramanlık 
duygularının açığa çıkarılması için görev üstlenen kişilerdir. Toy, şenlik, eğlence ve yolculuk molalarının dinlendirici ve eğlendirici işlevlerinin dışında savaş anlarında askerleri motive edici görevleri bulunmaktadır. Bunun yanı sıra davullar, kopuzlar, borular dönemin müzik ve eğlence kültürü içerisinde yer alan müzik aletlerindendir. Günümüz âşık atışması geleneğinin Bozkır hayatından kalan bir etkinlik türü olduğu belirlenmiştir.

Bozkır hayatındaki oyunların kuralları vardır ve bu kurallara uymak töreye uymakla eş değerdir. Oğlak kapma, okçuluk, nişancılık, güreş, at yarışı, kılıç oyunu gibi kuralları net bir şekilde belirlenmiş oyunların kurallarına muntazam şekilde uyulduğu görülmektedir.

Romanda yer alan oyun örneklerinin çoğu yetişkinler için uygulanan oyunlardır. Çocuklar için oynanan oyun türleri de yetişkinlerle aynı oyun örnekleridir. Yalnızca kullandıkları kılıç, ok, yay gibi aletler yetişkinlerin kullandıkları aletlerden farklılaşmaktadır. Kız çocukları da erkek çocukları gibi kılıç oyunu oynamakta, ok atmakta ve ata binmektedir. Bozkır hayatında cinsiyet açısından eşitlikçi bir profil çizilmektedir. Oyun kuramları içerisinde "yaşama hazırlık kuramı" bozkır hayatında yetişkin oyunları ile sonraki yaşamlarına hazırlanan çocukların oyunlara katılma amaçlarını tanımlayan bir yaklaşımdır. Çocuklar oyun yoluyla hayatın ileri dönemlerine ilişkin eylemlerin deneyimlerini yaparak gelecekteki yaşamlarına hazırlanmaktadırlar. Aynı çocuklar “sosyo-kültürel gelişim kuramı”nın gereği olarak oyun yoluyla Türk töresinin kurallarını ögrenmektedirler.

Kültür ile boş zamanları değerlendirme alışkanlıkları arasında güçlü bir ilişki bulunmaktadır. Türkler ilişki içerisinde bulundukları toplulukların kültürlerine alıştıkça kendi kültürlerinin gereklerini yerine getirmek konusunda zafiyete düşmektedir. Kendi kültüründen uzaklaştıkça boş zaman geleneklerinden uzaklaşmakta, boş zaman geleneklerinden uzaklaştıkça da kendi kültürlerine yabancılaşmaktadırlar. Esaret altında başka coğrafyalarda bile kendi kültürlerini korumak ve yaşatmak adına kendi törelerine has aktiviteleri sürdüren Türkler varken, kimliğinden uzaklaşan Türklerin hızla bunlardan ayrışıp özlerine yabancılaştıkları görülmektedir. Türklerin töresini, kimlikleri yansıtmaktadır. Birinden uzaklaşan diğerinden de uzaklaşmaktadır. Ülkelerini ve devletlerini terk etseler dahi kültürlerini terk etmeyen Türkler, boş zamanlarını da töreye uygun bir şekilde değerlendirmektedirler. Aslında geleneksel boş zaman değerlendirme etkinliklerini yaşatanların töreyi de yaşatanlar olduğu görülmektedir.

\section{Kaynakça}

Ardahan, F. (2016). Her yönüyle rekreasyon. Detay Yayınc1l1k.

Atsız, H. N. (2015). Bozkurtlar. Ötüken Neşriyat.

Bal, S. (2018). Gün olur asra bedel romanı ile bozkurtlar romanında mekân olarak bozkır. International Journal of Humanities and Education, 4(8): 307-322.

Caillois, R. (1961). Man, play and games. Thames and Hudson.

Çetin, A. (2010). Kutadgu Bilig'de aile kültüründe bir babanın oğul imajı ya da süregiden bellek/kültür. Milli Folklor, 22(85): 122-132.

Çetiner, H. (2019). Güncel animasyon uygulamaları (Oyunlar). Ö. Yayla \& E. Karaçar (Ed.), Rekreasyon ve Güncel Animasyon uygulamaları içinde (s.109-156). Detay Yayıncılık.

Evis, A. (2014). Hüseyin Nihal Atsı'ın romanlarında fantastiğin izleri. Mustafa Kemal Üniversitesi Sosyal Bilimler Enstitüsü Dergisi, 11(25): 13-36.

Gökalp, Z. (2017). Türk töresi. Ötüken Neşriyat.

Gökalp, Z. (2019). Yeni hayat. Ötüken Neşriyat. 
Güngör, E. (2003). Kültür değişmesi ve milliyetçilik. Hisar Yayınları.

Hazar, A. (2014). Rekreasyon ve animasyon. Detay Yayınc1lik.

Huizinga, J. (1995). Homo ludens oyunun toplumsal işlevi üzerine bir araştırma. (M. A. Kılıçbay, Çev.) Ayrıntı.

İzgi, Ö. (1977). Hunlar, Göktürkler ve Uygurlarda geleneksel festival ve eğlenceler. Tarih Dergisi. 31: 29-36.

Kafesoğlu, İ. (2018). Türk millî kültürü̈. Ötüken Neşriyat.

Leitner, M. J., \& Leitner, S. F. (2012). Leisure enhancement. Sagamore Publishing.

Öztürk Serter, G. (2018) Yapılandırılmış oyun terapisine dayalı geliştirilen psiko-eğitim programının boşanmış aile çocuklarının depresyon ve uyum düzeyleri üzerine etkisi [Yayımlanmamış doktora Tezi]. Ondokuz Mayıs Üniversitesi Eğitim Bilimleri Enstitüsü.

Tekin, A. (2016). Serbest zaman bağlamında oyun teorileri. S. Karaküçük (Ed.), Rekreasyon bilimi içinde (s.43-66). Gazi Kitapevi.

Tokuz, G. (2011). Gaziantep'te çocuk oyunları üzerine halkbilimsel bir inceleme [Yayımlanmamış yüksek Lisans Tezi]. Gaziantep Üniversitesi Sosyal Bilimler Enstitüsü.

Topdemir, R. (2012). Tarihi romanda zaman meselesi. International Journal of Social Science. 5(2): 291-303.

Torkildsen, G. (1991). Leisure and recreation management. E \& FN Spon.

Vygotsky, L.S. (1967). Play, and its role in the mental development of the child. Soviet Psychology, 5(3): 6-18. 